\title{
Comparative analysis of the frequency of lower urinary tract dysfunction among institutionalised and non-institutionalised children
}

\author{
UBIRAJARA BARROSO Jr, ANDERSON DULTRA, JOSÉ DE BESSA Jr, DANIELA G. BARROS, FABIO MARON, \\ DANILO V. BARROSO and EDSON DUARTE MOREIRA Jr \\ Division of Urology, Section of Paediatric Urology, Federal University of Bahia, São Rafael Hospital and Bahiana School of Medicine and Public \\ Health, Brazil \\ Accepted for publication 26 October 2005
}

\section{OBJECTIVES}

To evaluate the level of symptoms of lower urinary tract dysfunction (LUTD) in orphans in institutions, and compare these data with schoolchildren of the same age group who were not institutionalised, as LUTD in children is related to factors such as social isolation and low self-esteem, with other psychological changes also being cited, although it is unknown whether these problems are primary or secondary to the symptoms of LUTD.

\section{PATIENTS AND METHODS}

Children institutionalised in orphanages with no parental presence and who are isolated from a family environment are probably more sensitive to psychological disturbances.
Psychological changes have been associated with symptoms of urgency and urinary incontinence. Thus 89 orphans were compared with 143 schoolchildren not in institutions. A questionnaire was devised and completed by the care-taking staff in the orphanage, while for the schoolchildren the parents completed the questionnaire. The mean age in the institutionalised children was 7.9 years and that of the control group 7.8 years $(P=0.32)$. Thirty-nine $(44 \%)$ of the orphans were boys, vs 74 (54\%) of the control group $(P=0.17)$

RESULTS

The incidence of urgency, diurnal urinary incontinence, nocturnal enuresis and constipation in the orphans and in the control group were: $45(51 \%)$ and $57(40)(P=0.17)$, $36(40 \%)$ and $19(13 \%)(P<0.001), 39(47 \%)$ and $38(27 \%)(P=0.002)$, and $27(30 \%)$ and $43(30 \%)(P=0.76)$, respectively.

\section{CONCLUSION}

Children living in orphanages have a significantly higher level of diurnal urinary incontinence and nocturnal enuresis than those not in an institution.

\section{KEYWORDS}

bladder, children, dysfunction, neurogenic bladder, orphanage, incontinence

\section{INTRODUCTION}

Lower urinary tract dysfunction (LUTD) is clinically characterized by frequency and urgency or by infrequent voiding when the child has already completed toilet training, in the absence of neurological findings. It is an important clinical entity that is currently recognized as being a major cause of UTI in older children, for its association with VUR and as a risk factor for kidney scarring and arterial hypertension [1-3].

LUTD in children is related to psychological problems, social isolation and low self-esteem [4]. Nevertheless, it is still controversial in published studies whether these problems are primary or secondary to the symptoms of LUTD. Kolvin and Taunch [5] suggested that the cause of primary enuresis is principally biological, while the causes of secondary enuresis are largely psychosocial. Nevertheless, Van Gool et al. [6] showed that not all children with LUTD had psychological disturbances. They further found that not every child influenced by such factors as divorce, parental death or sexual abuse had LUTD.

Children institutionalised in orphanages with no parental presence and who are isolated from a family environment are probably more sensitive to psychological disturbances. If psychological problems originate from LUTD, children who live in orphanages would have a rate of LUTD symptoms similar to children not in an institution. The aim of the present study was to compare the LUTD symptom level in orphan children with those in individuals of the same age group from a public school population.

\section{PATIENTS AND METHODS}

A questionnaire was given to parents of public school children and to caretaker staff of an orphanage. Urinary symptoms such as urgency, daytime urinary incontinence (UI), bedwetting and constipation were evaluated. The symptoms defined were: urgency a strong desire to urinate accompanied by fear of leakage; daytime UI, the presence of urinary leakage due to an inability to hold urine; and constipation, a difficult, incomplete, or infrequent evacuation of dry, hard faeces. The data were collected by directly questioning the adults, to avoid any type of negative reaction in the children. To avoid interference in the sampling on the level of social or economic class, it was defined that the noninstitutional group would be from public schools; this sampling definition equalises the comparison to the orphan group. In December 2003 a random questionnaire was administered to the parents of students from a metropolitan public school. This period was chosen because it coincided with the enrolment period of these schools. In all, 143 questionnaires were given to this group. In 
March 2004, 89 questionnaires were administered to the caretakers of orphaned children in the same metropolitan area.

Children with any type of previous neurological problem, e.g. seizures, physical or mental impairment, or a history of neurological or psychiatric treatment, were excluded from the study. The results were compared statistically using chi-squared tests for proportions and $t$-tests for mean difference, with $P<0.05$ considered to indicate significant differences.

\section{RESULTS}

There were 39 boys and 50 girls (aged 4-11 years) in the institutional group, and 74 boys and 50 girls aged $4-11$ years in the control group. There was no statistical difference in sex distribution $(P=0.32)$ or age between the groups $(P=0.17)$. The number of children with urgency, daytime UI, bedwetting and constipation is listed in Table 1 ; there was a significant difference between daytime UI and bedwetting between the groups.

\section{DISCUSSION}

The causes of LUTD remain unclear; psychological changes and social stress are suggested in some studies as being a possible cause of UI [7-9]. There are also studies showing that psychological problems are secondary consequences of LUTD symptoms [10]. Lettgen et al. [11] showed that children with LUTD who have short dry periods ( $<1$ month), with no diurnal UI and bedwetting, have a greater risk of developing psychiatric problems.

It is fairly common, principally in more severe cases, to have an association of LUTD with psychological problems and family conflict. The parents, principally the father, tend to be intolerant and dominating. Divorce and alcoholism exacerbate the environment of conflict. The children are sometimes punished verbally and physically. From this can follow confusion, low self-esteem and depression, generated by fear of urinating in their clothing. Institutionalised children residing in orphanages can also have psychological problems; they have no family environment, with no parents because of either death or abandonment, and further have suffered profound social stress. From a psychological perspective, these children are more sensitive to all types of disturbances. As documented

\begin{tabular}{|c|c|c|c|c|}
\hline Symptom & $\begin{array}{l}\text { Institutional, } \\
\mathrm{n}(\%)\end{array}$ & $\begin{array}{l}\text { Not institutional, } \\
\mathrm{n}(\%)\end{array}$ & $P$ & $\begin{array}{l}\text { TABLE } 1 \\
\text { The rate of LUTS in the two }\end{array}$ \\
\hline Urinary urgency & $45(51)$ & $57(40)$ & 0.17 & groups of children \\
\hline Urge UI & $36(40)$ & $19(13)$ & $<0.001$ & \\
\hline Nocturnal enuresis & $39(47)$ & $38(27)$ & 0.002 & \\
\hline Constipation & $27(30)$ & $43(30)$ & 0.76 & \\
\hline
\end{tabular}

by Frank et al. [12], children in institutional care are extremely vulnerable to psychological problems. Orphanages put young children at greater risk of delayed language development and other developmental problems [13]. Children raised in institutions (compared to children raised by families) have lower intelligence quotient scores, difficulties forming and maintaining relationships with others, and poor self-esteem [13]. Also, in orphanages there are several problems related to staffing, including limited training and lack of appropriate supervision. If psychological distress was secondary to bladder dysfunction a similar rate of UI might be expected in orphans and schoolchildren. There was a higher rate of daytime UI (40\% vs 13\%, $P<0.001)$ and of bedwetting (47\% vs $27 \%$, $P=0.002)$ in the present institutional children living in orphanages, but no statistical difference in urgency between the groups, at $51 \%$ and $40 \%(P=0.17)$.

Constipation has been associated with bladder dysfunction; Schopfner [14] noted that constipation was associated with reflux, hydronephrosis, enuresis and urinary infection, a correlation also reported by Koff et al. [15]. On this basis, we included in the questionnaire an investigation of evacuation disturbances; there was no statistical difference between the groups (30\% in both groups, $P=0.76$; Table 1). Because daytime UI was more prevalent in the institutionalised children we expected a higher frequency of evacuation problems in this group, but this was not so. As faecal elimination problems are not easily obtained from the clinical history, and because the questionnaires were address to the caretakers in the institutional group, the real incidence might have been underestimated.

The present results show that children living in orphanages have a greater rate of daytime and night-time UI. The data suggest that the environment and the psycho-social living situation have a striking effect on LUT function. Andersson [16] cited the relationship between depression and detrusor overactivity, where a deficiency in serotonin (5-hydroxytryptamine) and its metabolism could be associated with LUTD. He also suggested that the administration of selective serotonin reuptake inhibitors in patients with no UI could, in turn, cause UI, especially in children.

In conclusion, children who live in orphanages have a significantly higher level of diurnal and nocturnal UI than those not in institutions. To our knowledge, this is the first study to provide epidemiological data on the symptoms of LUTD in institutionalised children who live in orphanages.

\section{CONFLICT OF INTEREST}

None declared.

\section{REFERENCES}

1 Barroso U Jr, Barroso VD, Jacobino $M$, Vinhaes AJ, Macedo A Jr, Srougi M. Etiology of urinary tract infection in schoolchildren. Int Braz J Urol 2003; 29: 450-4

2 Snodgrass W. Relationship of voiding dysfunction to urinary tract infection and vesicoureteral reflux in children. Urology 1991; 38: 341-4

3 Barroso U Jr, Jednak R, Barthold JS, Gonzalez R. Outcome of ureteral reimplantation in children with urge syndrome. J Urol 2001; 166: 1031-5

4 von Gontard A, Lettgen B, Olbing $H_{\text {, }}$ Heinken-Lowenau C, Gaebel E, Schmitz I. Behavioural problems in children with urge incontinence and voiding postponement: a comparison of a paediatric and child psychiatric sample. BJU Int 1998; 81 (Suppl. 3): 100-6

5 Kolvin I, Taunch J. A dual theory of noctural enuresis. In Kolvin I, MacKeith RC, Meadows SR eds, Bladder Control and Enuresis. Clinics in Developmental Medicine, No. 48/49. London: Spastics International Medical Publications, Heinemann, 1973: 156-72

6 van Gool JD, Hjalmas K, Tamminem- 
Mobius T, Olbing H. Historical clues to the complex of dysfunctional voiding, urinary tract infection and vesicoureteral reflux. The International Reflux Study in Children. J Urol 1992; 148: 1699-702

7 Zoubek J, Bloom DA, Sedman AB. Extraordinary urinary frequency. Pediatrics 1990; 85: 1112-4

8 Bass LW. Pollakiuria, extraordinary daytime urinary frequency: experience in a pediatric practice. Pediatrics 1991; 87: 735-7

9 Watemberg N, Shalev H. Daytime urinary frequency in children. Clin Pediatr (Phila) 1994; 33: 50-3

10 Fergusson DM, Horwood ப, Shannon FT. Factors related to the age of attainment of nocturnal bladder control: an 8-year longitudinal study. Pediatrics 1986; 78: 884-90

11 Lettgen B, von Gontard A, Olbing H, Heiken-Lowenau C, Gaebel E, Schmitz I. Urge incontinence and voiding postponement in children: somatic and psychosocial factors. Acta Paediatr 2002; 91: 978-86

12 Frank DA, Klass PE, Earls F, Eisenberg L. Infants and young children in orphanages: one view from pediatrics and child psychiatry. Pediatrics 1996; 97 : 569-79
13 Fuhmann BS, Munchel RL. Residential care in a rapidly changing environment. Caring 1995; 11: 31-5

14 Schopfner CE. Urinary tract pathology associated with constipation. Radiology 1968; 90: 865-77

15 Koff SA, Wagner TT, Jayanthi VR. The relationship among dysfunctional elimination syndromes, primary vesicoureteral reflux and urinary tract infections in children. J Urol 1998; 160: 1019-22

16 Andersson KE. New pharmacologic targets for the treatment of the overactive bladder: an update. Urology 2004; 63: 32-41

Correspondence: Ubirajara Barroso Jr., Rua Alameda dos Antúrios, 212, apt 602, Cidade Jardim, Salvador, Bahia, Brazil 40280620. e-mail: ubarroso@uol.com.br

Abbreviations: LUTD, lower urinary tract dysfunction; UI, urinary incontinence

\section{APPENDIX}

The questionnaire (translated from Portuguese)
1. Name:

2. Date birth:

3. Institution:

4. Date of the first day in the institution:

5. Gender: 1. ( ) Male 2. ( ) Female

6. Does the child hurry to the toilet in fear of wetting his/her pants (leakage)? 1. ( ) No. 2. ( ) Yes

7. The child occasionally wets his/her pants during the day? 1. ( ) No. 2. ( ) Yes 8. If the last answer was yes, How many times does this occur? 1. ( ) Every day 2. ( ) 2-3 times/week 3. ( ) less times than 2-3 times/ week

9. Does the child urinate while sleeping (bedwetting)? 1. ( ) No. 2. ( ) Yes 10. If the last answer was yes, How many times does this occur? 1. ( ) Every day 2. ( ) 2-3 times/week 3. ( ) less times than 2-3 times/week

11. Does the child have hard, dry bowel movements? 1. ( ) No. 2. ( ) Yes

12. Does the child have a history of urinary infection? 1. ( ) No. 2. ( ) Yes

13. Does the child have any neurological or psychiatric problems, such as seizures, physical or mental impairment? 1. ( ) No. 2. ( ) Yes 3. ( ) I do not know 14. Has the child have ever visited a neurologist or psychiatrist? 1. ( ) No. 2. ( ) Yes 3. ( ) The visits are part of institutional policy 